\title{
LIV. On condensation nuclei produced by the action of light on iodine vapour
}

\section{Gwilym Owen M.A. D.Sc. \& Harold Pealing M.Sc.}

To cite this article: Gwilym Owen M.A. D.Sc. \& Harold Pealing M.Sc. (1911) LIV. On condensation nuclei produced by the action of light on iodine vapour, Philosophical Magazine Series 6, 21:124, 465-479, DOI: 10.1080/14786440408637054

To link to this article: http://dx.doi.org/10.1080/14786440408637054

曲 Published online: 21 Apr 2009.

Submit your article to this journal $[\pi$

Џ Article views: 3

Q View related articles $\square$ 


\section{$\left[\begin{array}{ll}465 & ]\end{array}\right.$}

LIV. On Comlensation Aruclei produced by the Action of Light on Iodine Vapour. By GWILym OWEN, M.A., I).Sc., and Harodid Pealing, M.Se., Cniversity of Liverpool *

TROM experiments made by G. Owen and A. Ll. Hughes 1 (Phil. Mag. Oct. 1907, June 1908) it seems that the gas evolved by a soliditied mass of carbon dioxide previously condensed in a dry and dust-free condition contains laree numbers of nuclei, the presence of which can be shown by their ability to act as centres for the condensation of supersaturated water-vapour. This fact suggests that the sublimation of solid $\mathrm{CO}_{2}$ consists not merely in the escape of separate gaseous molecules, but also in the liberation of large numbers of relatively large molecular aggregations. The question arises as to whether the same is true for other subliming substances, and it was during the course of experiments designed to test this point that the effects described in the present paper were observed.

Experiments were made with camphor, naphthalene, benzoic acid, and iodine-the method being to pass a current of dust-free air through a tube containing one of these volatile substances, and then to test the air for nuclei by suddenly expanding it in a bulb containing distilled water.

In fig. $1, A$ is the glass tube containing the substance to

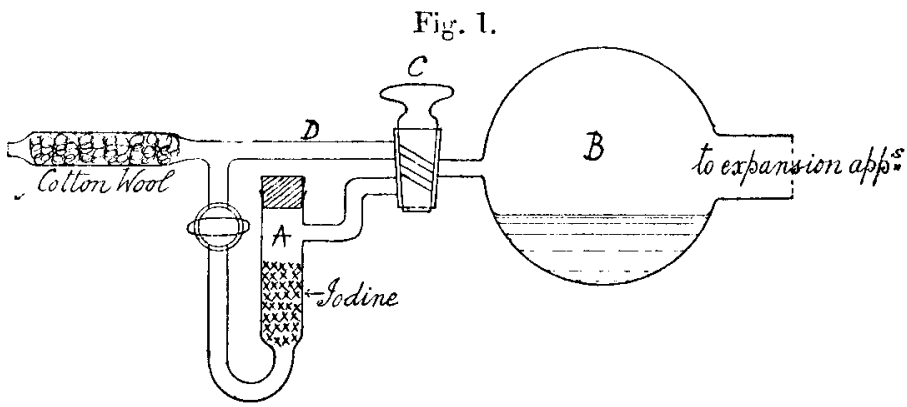

be tested. The air swept through this tube was first rendered dust-free by a plug of cotton-wool as shown. The cloudchamber $B$ was a glass bulb some $6 \mathrm{cms}$. in diameter and was sealed on to a Wilson expansion apparatust, the piston of which worked in distilled water. The whole apparatus to the right of the tap $\mathrm{C}$ was made of glass. Any clouds produced in $B$ were rendered visible by tocussing on the bulb the light from a Nernst lamp. If we take as a

* Communicated by the Authors.

† C. T. R. Wilson, Camb. Phil. Soc. Proc. ix. p. 333 (1897). 


\section{Dr. G. Owen and $\mathrm{Mr}$. H. Pealing on Condensation}

measure of the expansion the pressure-fall-that is, the difference between initial and final pressure of the gas in the apparatus, - then, as is well known *, there is no condensation in the body of the gas when the pressure-fall is less than $15 \mathrm{cms}$. of mercury. When the expansion is between $15 \mathrm{cms}$. and 20 cms. a few scuttered drops are observed ("rain-like" condensation), the nuclei in this case being the few ions always present in the gas. On subjecting the gas to a pressure-fall over $20 \mathrm{cms}$., a dense fog is obtained. The nuclei on which this fog forms are generally regarded as being minute drops of water continually being formed from the saturated water-vapour. In the present paper wo shall refer to the above effects as the "Wilson effects."

\section{Results of the Tests made with Camphor, Naphthalene, Benzoic Acid, and Iodine.}

With camphor, naphthalene, benzoic acid, the showers or clouds obtained on expansion were identical with the usual Wilson effects. Evidently, then, these substances do not sublime in the form of molecular aggregations sufficiently large to act as condensation nuclei. C. Barus $\dagger$ had previously obtained a similar result with a somewhat different apparatus for camphor and naphthalene. With iodine, however, we obtained very marked effects, as is shown in the following table. The figures in the columns marked

TABLE I.

\begin{tabular}{|c|c|c|c|}
\hline \multicolumn{2}{|c|}{$\begin{array}{l}\text { Cloud-chamber filled with pure moist } \\
\text { dust-free air. }\end{array}$} & \multicolumn{2}{|c|}{$\begin{array}{l}\text { Cloud-cinamber filled with air } \\
\text { which had passed orer iodine. }\end{array}$} \\
\hline $\begin{array}{l}\text { Pressure-fall } \\
\text { in cuis. }\end{array}$ & $\begin{array}{c}\text { Obsarvation. } \\
\text { (Ordinary Wilson effects.) }\end{array}$ & $\begin{array}{l}\text { Pressure-fanl } \\
\text { in cms. }\end{array}$ & Observation. \\
\hline $15 \cdot 0$ & 0 & $15 \cdot 0$ & Few drops. \\
\hline $16 \cdot 5$ & Few drops. & $16 \cdot 5$ & Thin shower. \\
\hline $17 \cdot 5$ & Thin shower. & $17 \cdot 5$ & Good showel. \\
\hline $18 \cdot 5$ & Good shower. & $18 \cdot 5$ & Tinted cloud. \\
\hline $19 \cdot 5$ & Very dense shower. & & \\
\hline $20 \cdot 5$ & Fog. & & \\
\hline
\end{tabular}

* C. T. R. Wilson, Phil. Trans. A. rol. cxxxix. (1897).

+ C. Barts, "Condensation of Vapor as induced by Nuclei and Ions.' (Curnegie Institution of Washington, May 1907.) 
Nuclei produced by Action of Light on Iodine Vapour. 467

"pressure-fall" are centimetres of mercury, and, as already explained, may be taken as a measure of the expansion. For the purpose of comparison the Wilson effects obtained with our apparatus are first given.

The above table shows that the presence of the iorline vapour in the cloud-chamber produces a considerable increase in the density of the clouds obtained, and that the effect of the iodine is specially marked for pressure-fall of $18.5 \mathrm{cms}$.

The influence of the iodine was found to be very persistent, sweeping in fresh air through the by-path $D$ for several hours failed to get rid of the effect. In fact, it was found necessary to take the apparatus down and wash it thoroughly to make it give once more the ordinary Wilson effects. Later experiments (described below) showed that the influence of the iodine ultimately disappears if the apparatus is allowed to stand in bright light for tbree or four days.

When the above effect was first obtained, we were naturally led to believe that iodine, in contradistinction to the other substances tried, does sublime in the form of particles sufficiently large to act as condensation nuclei. But this conclusion was upset by the following modification of the experiment. Between the iodine reservoir and the cloud-chamber a tube containing a long plug of glass-wool was inserted, in order to see if the iodine particles could be trapped and prevented from reaching the cloud-chamber. After sweeping air and iodine vapour through this tube for two minutes, the clouds obtained with a pressure-fall of $18 \%$ were now much denser than before. Further, the passage of the iodine vapour was observed to produce a discoloration of the wool, and, finally, when the latter was coloured through its whole length, heavy clouds were obtained for quite small expansions corresponding to a pressure-fall of less than $10 \mathrm{cms}$. This last effect was at first regarded as showing that when the iodine is dispersed in the form of minute crystals in the interstices of the wool the mechanical action of the air-current results in small solid particles of iodine being dislodged from these crystals and carried over into the bulb. This view, however, was shown to be erroneous by the following subsequent observations:-

(1) The glass-wool very soon lost its power of giving rise to the larger nuclei.

(2) On expanding without previously illuminating the gas in the cloud-chamber the results were just the same as the Wilson effects.

Thus the effects obtained with the iodine are not mechanical at all, but photochemical. 
A large number of observations have since been made (a) when the iodine vapour was placed inside the clondchamber itself; $(b)$ when iodine vapour was swept through glass-wool before admission into the apparatus. It will be convenient to discuss the two cases separately, although, as will be shown, they are probably intimately connected.

\section{Experiments with Lodine placed in the Cloud-Chamber itself.}

When studying the effect of iodine placed inside the cloudchamber, the apparatus shown in fig. 2 was found convenient.

Fig. 2.

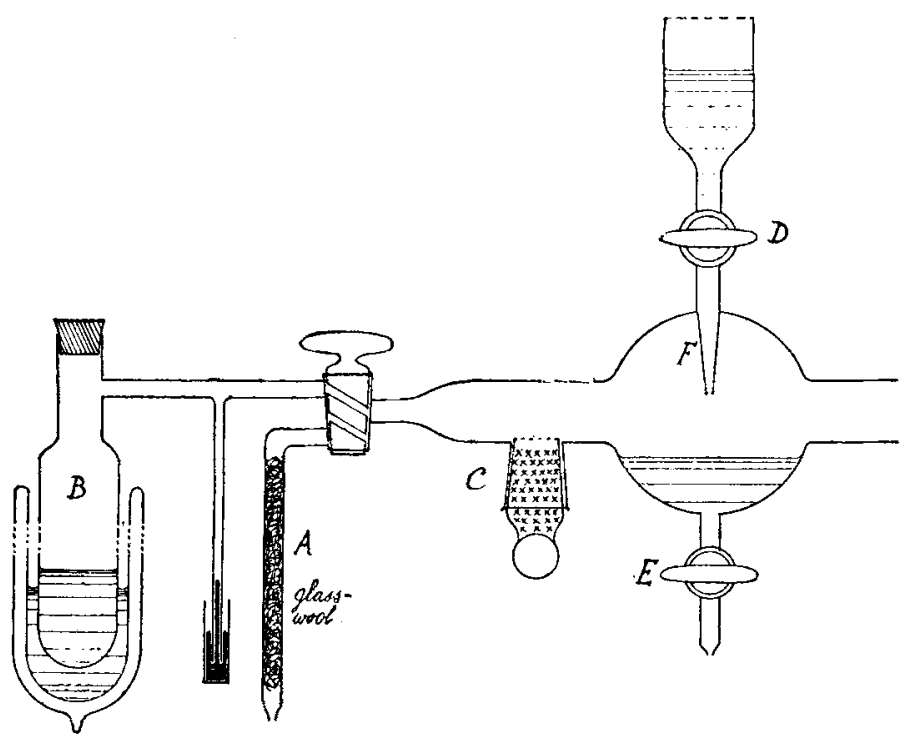

The apparatus conld be filled either by filtered laboratory air drawn in through $A$ or hy air from boiling liquid air stored in B. As a matter of fact, both these sources of dustfree air gave practically the same results. The apparatus was first calibrated with pure air and then iodine vapour was introduced by placing a few crystals in the hollow tap C. The taps D, E allowed fresh distilled water to be admitted when desired. In order to study the effect of light, the cloud-chamber and expansion apparatus were wrapped in black cloth. The covering of the cloud-chamber was provided with two vertical slits, one on each side; the one slit 
Nuclei produced ly Action of Light on Iodine Vapour. 469

admitted the light, and the other permitted an inspection of the cloud obtained. The slits were provided with flaps, which could be closed when it was desired to keep the apparatus in complete darkness.

Table II. shows the effect of light. The results given in the last column were obtained by producing the expansion in the dark and then admitting the light immediately afterwards.

TABLE II.

\begin{tabular}{|c|c|c|c|c|c|}
\hline \multicolumn{2}{|c|}{$\begin{array}{l}\text { No Iodine in the } \\
\text { Apparatus. Light on } \\
\text { Bulb continuously. }\end{array}$} & \multicolumn{2}{|c|}{$\begin{array}{l}\text { Iorline in the } \\
\text { Apparatus. Light on } \\
\text { Bulb continuously. }\end{array}$} & \multicolumn{2}{|c|}{$\begin{array}{l}\text { Iodine in Apparatins. } \\
\text { Expansion made in the } \\
\text { clark. Light put on } \\
\text { immediately afterwards. }\end{array}$} \\
\hline $\begin{array}{c}\text { Pressure- } \\
\text { fall. }\end{array}$ & Observation. & $\begin{array}{l}\text { Pressure- } \\
\text { fall. }\end{array}$ & Observation. & $\begin{array}{l}\text { Pressure- } \\
\text { fall. }\end{array}$ & Observation. \\
\hline ...... & $\ldots \ldots$ & 145 & Few drops. & $14 \cdot 2$ & 0 \\
\hline 155 & Few drops. & $15 \cdot 5$ & Fair shower. & ...... & $\ldots \ldots$ \\
\hline $17 \cdot 5$ & Thin shower. & $17 \cdot 5$ & Dense shower. & 175 & Thin shower. \\
\hline $18 \cdot 5$ & Good shower. & $18 \cdot 5$ & Coloured cloud. & $18 \cdot 5$ & Good shower. \\
\hline
\end{tabular}

The above table shows clearly :-

(a) That the nddition of the iodine causes an immense number of frech nuclei to appear.

(b) That the majority of the nuclei are small and consequently reciuire a large expansion corresponding to a pressure-drop of $18.5 \mathrm{cms}$. to catch them.

(c) That all these nuclei are wholly produced by the action of light, for when the expansions are made in the dark the effects observed on admitting the light immediately afterwards are the same as in the absence of iodine.

These effects were obtained with a Nernst lamp as the source of illumination. Other modes of illumination-arc lamp, fishtail burner, Nernst light screened by red glass, and diffused daylight-were tried with the same results. In the last case the clonds were observed by illuminating the bulb with a Nernst lamp after the expansion had been made. 
Experiments on the Growth of the Nuclei in the Light and their Decay in the Dark.

Tahle III. shows how the density of the cloud depends upon the duration of the illumination.

TABLE III.

Duration of illumination.

0

About $\frac{1}{4}$ eecond.

1 second.

2 seconds.
Result of the Expansion. Pressure-fall $=18 \cdot 5$ cms.

Good shower (=Wilson effect).

Denze shower.

Cloud.

Cloud (same as above).

Thus the nuclei grow under the influence of the light and attain a maximum size in less than one second.

Table IV. shows that the nuclei disappear very quickly after their formation. The bulb was illuminated in each case for the same period and then kept in the dark for various intervals before expansion.

\section{TABLE IV.}

\begin{tabular}{|c|c|}
\hline $\begin{array}{l}\text { Period for which the Nuclei } \\
\text { were kept in the dark } \\
\text { betore expansion. }\end{array}$ & $\begin{array}{l}\text { Result of the Expansion. } \\
\text { (Pressuro-fall }=18.5 \mathrm{cms} \text {.) }\end{array}$ \\
\hline 3 minutes. & Good shower. Same as \\
\hline 1 minute. & Good shower. $\}$ Wilson effects. \\
\hline 30 seconds. & Very dense shower. \\
\hline 10 seconds. & Cloud. \\
\hline 0 & Cloud. \\
\hline
\end{tabular}

Thus nearly all the nuclei live for ten seconds, but all lave disappeared in one minute. This may be due to the nuclei diffusing to the walls of the vessel, or to their actual break up. If the latter is the correct explanation, evidently the substance forming the nuclei is very unstable. 
Influence of the Gas in the Expansion Apparatus.

Air, hydrogen, carbon dioxide, coal-gas, and oxygen were tried in turn in the expansion apparatus. In each case the upparatus was first calibrated before introducing any iodine in order to study the normal Wilson effects in these gases. With hydrogen, $\mathrm{CO}_{2}$, and coal-gas, the introduction of the iodine produced absolutely no change. On the other hand, in the case of oxygen, the iodine gave rise to clouds similar to (possibly a little denser than) those obtained with air. Thus the presence of oxygen is necessary to the formation of the nuclei.

\section{Alcohol in the Expansion Apparatus.}

Some experiments were tried in which the water in the expansion apparatus and in the cloud-chamber was replaced by alcohol. With this liquid the normal Wilson effects begin at a pressure-fall of $10 \mathrm{cms}$, and fogs are obtained for a pressure-fall of about $12 \mathrm{cms}$. No increased effect could, however, be detected on admitting iodine. In fact, when the iodine had been in the apparatus for a day or two so that the alcohol had developed a bright yellow colour by the solution in it of some iodine rapour, the Wilson effects at any given expansion were then distinctly smaller than they were initially.

\section{Behaviour of the Nuclei in an Electric Field.}

In order to ascertain if the nuclei are charged, a clondchamber containing a horizontal platinum disk was constructed, the distance between the disk and the water surface being about $1.5 \mathrm{cms}$. A potential difference of 230 volts could be established when desired between the disk and the water. We could, however, detect no evidence of any motion of the nuclei under the electric force, for their rate of disappearance in the dark was the same with the field on as without. It may be concluded, therefore, that the nuclei do not carry an electric charge.

\section{Diminution of the Effect with Time.}

We noticed early on in the course of the experiments that the coloured clouds obtained with the iodine in the apparatus become less and less dense as time goes on. $\mathrm{By}_{\mathrm{y}}$ the second day the result of an expansion of 18.5 is only a "dense shower." This decay continues from day to day, until by the fourth or fifth day the effect obtained is actually smaller than the normal Wilson effect for the same expansion. It was found, in addition, that the effect of the 
iodine decreases much more rapidly when the apparatus is kept unshielded in bright diffused daylight than when kept in the dark. If the apparatus be taken down when in this non-sensitive state and thoroughly rinsed out with distilled water, the large effects already described once more make their appearance when iodine is admitted.

The following possible canses of the disappearance of the effect naturally suggested themselves and were investigated in turn :-

(1) That some change took place in the properties of the iodine itself, say through its becoming damp. Introducing fresh iodine, however, failed to bring back the original clouds.

(2) Thinking that possibly the nuclei might be due to an action of the iodine vapour on some impurity brought into the apparatus when it was filled with air, and that the disappearance of the effect in the course of a few days was due to this impurity being all used up, we tried admitting a fresh supply of air. On two or three nccasions fresh air did partly bring back the clouds, bnt generally this was not the case, both air from boiling liquid air and dusty laboratory air being equally in effective.

(3) Again, it was thought possible that the original clouds were due to an action of the iodine on vapours evolved by the vaseline lubricating the taps. But we found that iniroducing fresh vaseline into the apparatus produced no change. Various other possible sonrces of impurity, snch as tap-grease, indiarubber, red wax, cotton-wool, were placed in the apparatus. In every case there was no increased effect.

(4) Again, we thought that the film of iodine which naturally forms in time on the sides of the cloud-chamber might possibly cut off the effective part of the light entering the bulb. But driving off this film by gently heating the glass failed to bring back the original clonds.

(5) Again, it is well known that the value of the expansion required to catch nuclei of a given size depends upon the nalure and condition of the liquid in the clondchamber. Now, after the iodine has been in the apparatus for two or three days, the water in the cloudchamber develops a bright yellow colour owing to the solution in it of some of the iodine vapour. That the disappearance of the clouds is not due to this change in the water was shown in two ways:-

(a) The coloured water in the cloud-chamber was drained off through the tap $\mathrm{E}$ and fresh distilled water admitted through D. This process, however, had no effect. 
(b) A small quantity of radium was placed near the cloud-chamber and the minimum expansion required to catch the ions so produced carefully determined, first before any iodine has been introduced, and afterwards when the water in the apparatus had become strongly coloured by the iodine. The condensation on the ions was found to start at exactly the same expansion in both cases*. Hence the vapour-pressure of the water is not appreciably altered by the iodine.

(b) It has already been mentioned that the clouds after their disappearance are brongit back by rinsing the apparatus out atresh with distilled water. We bave also stated that admitring fresh water into the cloud-chamber through the tap D (fig. 2) is without effect. The two statements may appear contradictory. But an inspection of fig. 2 shows that there is a difference between the two operations. As may be seen from the figure, the water enters the apparatus through a nozzle $F$ projecting into the bulb, and consequently settles in the bulb without flowing down the wills. With an earlier form of cloud-chamber, in which the nozzle $F$ was absent, the water on admission ran down the sides of the bulb, and in this case the clouds were found to have been partly brought back. But the experiments with the cloud-chamber of fig. 2 show that this increase in the effect was due not so much to the changing of the water in the apparatus as to the rinsing of the glass walls by the water as it flowed into the bulb.

* Talring as the neasure of the expansion the ratio of the final to the initial rolume of the gas, we found that in our apparatus the mininum expansion required to catch the ims produced by radium was $1 \cdot 22$. C. '1'. R. Wilson (Camb. Phil. Soc. Proc. vol. ix.) gives the same value for the same form of apparatus. It has alrendy been mentioned that the ordiuary Wilson effect was observed in our experiment to be smaller when the apparatus had had iodine in it for some days than it is for the same expansions in an apparatus free from iodine. And yot the experiment with the radium shows that the ionic condensation commerces at the same point in the two cases. This fact suggests that the spontaneous isnization in a closed space is reduced by siturating the space with iodine vapour. A similar effect was noticed in the experiments with alcohnl. We propose investigating this print further. It is possible that there may be a connexion between this decrease in the Wilson effects and the result obtained by Henrr (Proc. Camb. Phil. Soc. 1897) in his experiments on the "Effect of Ultra-Violet Light on the Conductivity of Indine Vapour." Henry found that the discharge of ions from a wetal plate when illuminated by ultrit-violet liglat was greatly reduced by admitting jodine vapour into the jonization-chamber, bat he was uncertain as to whether this was a real effect or a spurious one due to the werkening of the light in its passagige through the vapour.

Phil. Mag. S. 6. Vol. 21. No. 124. April 1911. 2 I 


\section{Dr. G. Owen and Mr. H. Pealing on Condensation}

From a consideration of the above we are led to regard as follows the disappearance of the clouds and their reappearance on washing the apparatus. As will be seen later on, the nuclei probably result from the production of some substance which is deposited on the walls of the apparatus, and it is also likely that the action ceases when a certain amount of this substance has been formed. The flow of water over the glass would remove this deposit and allow the action to proceed as before.

The view that the glass plays a part in the production of the clouds is supported by the results of experiments made with glass-wool. A passing reference to these experiments has already been made. We shall now consider them in greater detail.

\section{Experiments with Glass-ucool.}

It has already been stated that when the iodine has been in the apparatus for a few days the coloured clouds obtained for an expansion corresponding to a pressure-drop of $18.5 \mathrm{cms}$. entirely disappear, and that the introduction of a number of foreign substances into the apparatus failed to bring the clouds back. We found, however, that the introduction of a plug of glass-wool gave rise to a cloud at a pressure-fall of $18 \cdot 5$. "But after the wool had been in the apparatus for some twenty-four hours, the effect had again disappeared. Evidently, then, something was introduced with the glass-wool which for a time facilitated the production of nuclei. In order to ascertain whether this was accidental or whether it was a general property of glass-wool, we obtained through Messrs. J. H. and S. Johnson, of Liverpool, three different lots of pure glass-wool, guaranteed to have been supplied to them by three different makers. We found, however, that plugs of each specimen when placed in the apparatus brought back the clouds. Clearly, then, the property is general.

But the most effective way of making evident this action of the glass-wool is shown in fig. 3 .

If a slow stream of air be drawn into the cloud-chamber through this arrangement, a dense fog is obtained for a pressure-drop of 18.5 . Further, when the glass-wool has become coloured by the iodine along its whole length, clouds are obtained for much smaller expansions. Referring to Table III., it is seen, too, that illumination for so short an interval as one second is sufficient to produce the nuclei canght with a pressure-drop of $18 \cdot 5$. On the other hand, we found that to produce the large nuclei caught by small 
Nuclei proluced by Action of Light on Iudine I'apour. 475

expansion, the light had to be kept on for half a minute or more. This shows that the larger nuclei result from the growth of the smaller nuclei under the influence of the light.

Fig. 3.

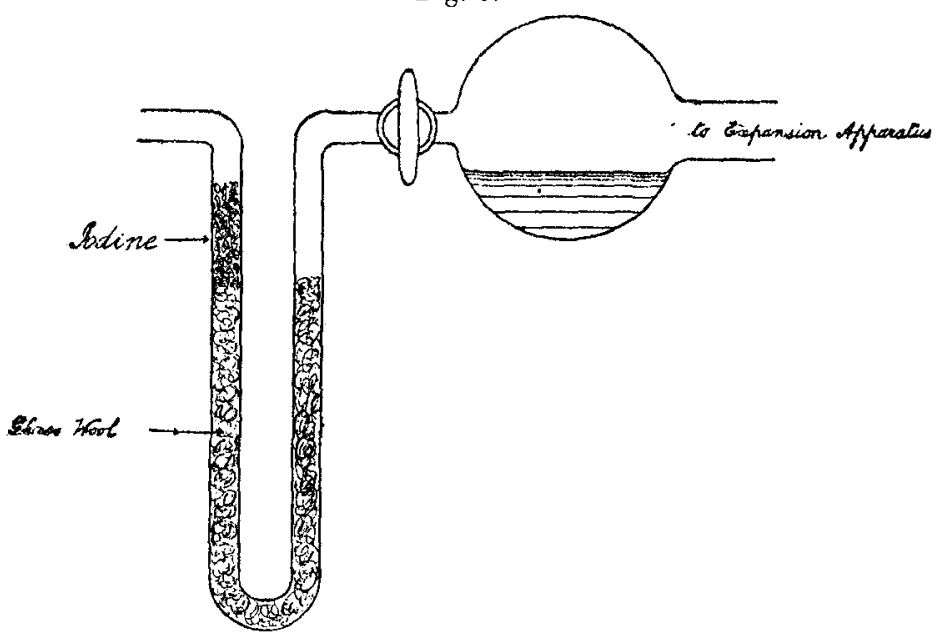

The clonds obtained at large expansions become less dense as time goes on, showing that the glass-wool gradually loses its efficiency. Further, the decrease in the density of the clouds at large expansions is accompanied by the total disappearance of the clouds of small expansions. This shows that the nuclei only succeed in attaining a considerable size when their number is very large.

\section{Discussion of the Results.}

These experiments with the glass-wool suggest that the production of the nuclei when the iodine is put directly into the cloud-chamber (fig. 2) is influenced by the condition of the glass walls of the apparatus.

It now remains to consider the source of this influence. In the first place, it is not probable that the clouds obtained when the iodine is placed in the cloud-chamber are due to the presence of urganic impurities on the glass, for they were invariably produced when the apparatus had previously been carefully washed with nitric acid and distilled water. And if this were the case it is difficult to see how the process of rinsing the apparatus with distilled water could bring back the clouds after they had once disappeared. On the other hand, the glass-wool itself is rendered less efficient as an aid 


\section{Dr. G. Owen and Mr. H. Pealing on Condensation}

to the formation of the nuclei by soaking it in strong nitric acid and then washing it with distilled wator. A small plug of glass-wool so treated did not cause a cloud when placed (in a dry condition) in the cloud-chamber. This same treatment, however, did not prevent the process of sweeping the iodine vapour through a long plug of it (as in fig. 3) from greatly increasing the density of the cloud at 18.5 pressure-fall, although it entirely stopped the formation of the large nuclei canght at small expansions.

If the nuclei originate as a surface action at the glass surface, this effect of the nitric acid on the glass-wool may be regarded in two ways:- $(a)$ That the acid alters the catalytic properties of the surface of the glass-wool, or (b) that it partly removes from it some substance the presence of which aids the formation of the nuclei. One would not expect glass-wool to contain an "impurity" in the ordinary sense of the word. It is well known, however, that there is an action between glass and pure water resulting in the formation of minute traces of $\mathrm{NaOH}$ at the surface. Supposing for a moment that the production of the nuclei depends upon this action, it is not unreasonable to suppose that artificially increasing the alkalinity at the glass surface would increase the number of nuclei produced. To test this point the apparatus was rinsed out with a weak solution ( 5 per cent.) of $\mathrm{NaOH}$ and then worked with this same solution in the bulb and expansion cylinder instead of distilled water, as in the previous experiments. Under these circumstances we found the iodine to be entirely without effect, for the nucleation was identical with the Wilson effects which we studied before introducing the iodine. Thus the nuclei are not due to the minute traces of $\mathrm{NaOH}$ usually present on moist glass; or, at all events, the degree of extra alkalinity that we happened to try, instead of facilitating the production of nuclei, prevented it completely. We also found that treating the apparatus in the same way with a dilute solution of $\mathrm{H}_{2} \mathrm{SO}_{4}$ prevented the production of the nuclei.

We thus find it difficult to say definitely what the nuclei are. They are evidently minute particles of some unstable compound requiring the co-presence of iodine-vapour, oxygen, and water-vapour for its production.

The effect is clearly photochemical in character, and in all probability belongs to that class of phenomena studied by Tyndall *, Aitken $\dagger$, and C. T. R. Wilson $\ddagger$. Tyndall found

* Tyndall, I'hil. Trans. vol. clx. p. 333 (1870).

$\dagger$ Aitlsen, Proc. Roy. Soc. Edin. vol. xxxix. i. p. 15 (1897).

$\ddagger$ Wilson, Phil. Trans. vol. excii. p. 403 (1890). 
that ultra-violet light caused clouds to form without expansion in air containing traces of amyl nitrite, iodide of allyl, and other vapours.

Aitken found that clouds are produced in $\mathrm{NH}_{3}, \mathrm{H}_{2} \mathrm{SO}_{3}$, $\mathrm{H}_{2} \mathrm{~S}, \mathrm{HCl}$, and $\mathrm{Cl}_{2}$ when expanded after exposure to sunlight.

(. T. R. Wilson showed that the action of ultra-violet light on pure moist air or oxygen produced condensation nuclei which grew under the influence of the light, and with very intense light he obtained clouds without any expansion at all. Wilson suggested that the clouds obtained by him are due to the formation of $\mathrm{H}_{2} \mathrm{O}_{2}$, which, by dissolving in the drops as they form, lowers the vapour-pressure and thus makes it possible for the drops to grow where drops of pure water would evaporate.

Bevan * again, in his experiments on the "Combination of Hydrogen and Chlorine under the Influence of Light," found that some substance is produced by the action of the light on the chlorine and water-vapour which acts as condensation nuclei, and that the formation of this intermediate substance is necessary for the production of the $\mathrm{HCl}$.

With regard to the nuclei described in the present paper, it is possible that the reactions going on under the influence of the light are as follows :-

$$
\begin{aligned}
& \mathrm{H}_{2} \mathrm{O}+\mathrm{I}_{2} \rightarrow \mathrm{HI}+\mathrm{HIO}, \\
& \mathrm{HIO}+\mathrm{O}_{2} \rightarrow \mathrm{HI}+\mathrm{O}_{3} ;
\end{aligned}
$$

or it may be a reaction in which the iodine is oxidized directly. Moreover, it is difficult to say which of the products of such reactions would actually form the nuclei. Ozone, of course, is known to give rise to clouds, but, according to Meissner $t$, only as a consequence of reactions by which some of the ozone is destroyed.

The above reactions, being reversible, would cease when a certain amount of the products had been formed. This fact would explain why no clouds are obtained when the jodine has been for some days in the apparatus. It would also account for the reappearance of the clouds on washing the apparatus, for such treatment would remove the products of the reaction and allow it to go on once more. From this point of view the effect of introducing a plug of glass-wool into the cloud-chamber is readily understood, for the fibres

* Bevan, Phil. Trans. vol. ccii. A. p. 347 (1903).

$\dagger$ Quoted by C. T. R. Wilson, Phil. Trans, vol. cxcii, p. 428 (1899). 
will present a considerable area of fresh glass surface at which the action may proceed. On the other hand, the part played by the glass-wool in the experiments where the iodine vapour is swept through it before admission into the cloud. chamber is not quite so clear. It eithor means that the glass fibres by some preparatory catalytic action on the iodineladen air facilitate the subsequent formation of the nuclei, or it means that there is some unexpected "impurity" in the glass-wool, which, reacting with the iodine, produces the results described. Since clean glass is known to affect certain chemical reactions, we are inclined to adopt the former view.

Summary of the Main Results.

In contradistinction to the results previously obtained with solid $\mathrm{CO}_{2}$, we find that

(1) Camphor, napthalene, benzoic acid, and iodine do not sublime in the form of particles sufficiently large to act as condensation nuclei for water-vapour. But

(2) When moist air (or oxygen) containing iodine vapour is illuminated, nuclei are produced, possessing the following properties :-

The nuclei are very unstable, disappearing in a few seconds in the dark. They do not carry an electric charge. They are not obtained except in the presence of oxygen and watervapour. They grow under the action of the light, but, generally, do not attain a size greater than that requiring a pressure-fall of $18.5 \mathrm{cms}$. in order to catch them. The light required for their production need not be very intense nor of a high degree of refrangibility.

(3) No nuclei are produced after the iodine has been in the apparatus for some days. The cessation of the action is probably due to a state of chemical equilibrium having been attained. The equilibrium is destroyed by rinsing the glass walls of the apparatus with water.

(4) Glass-wool possesses the peculiar property of facilitating the formation of the nuclei, the number produced when iodine-laden air is admitted into the apparatus through a plug of glass-wool being much greater than the number nbtained on placing iodine directly in the cloud-chamber. This property becomes less and less marked as the wool gets more and more saturated with the iodine. The action of the glass-wool is regarded either as being of a catalytic nature or as evidence of the wool being an unexpected source of 
Potentials required to produce Discharges in Guses. 479 contamination for the iodine vapour during its passage through it.

In conclusion, we have pleasure in expressing our best thanks to our colleague, Dr. H. Bassett, for much valuable information on points pertaining to the chemistry of the subject.

Holt Physics Laboratory,

Liverpool University.

Feb. 8th, 1911.

LV. Investigation of the Potentials required to produce Discharges in Gases at Low Pressures. By A. B. Meserver, New College, Oxford ${ }^{*}$.

Sparking Potentials between Concentric Cylinders.

THE theory of sparking has been completely worked out for uniform fields only, but it would appear that some additional light might be thrown on the processes of ionization that take place at very low pressures from experiments on sparking in a non-uniform field. These experiments were undertaken with this end in view, and the field between concentric cylinders was seiected as the simplest form of a field that is not uniform. Some preliminary experiments $t$, which were made in this laboratory, with concentric cylinders, showed, as might have been expected, that the sparking potential varied with the direction of the field, and the curves obtained in the two cases crossed at a point near the minimum sparking potential.

Fig. 1.

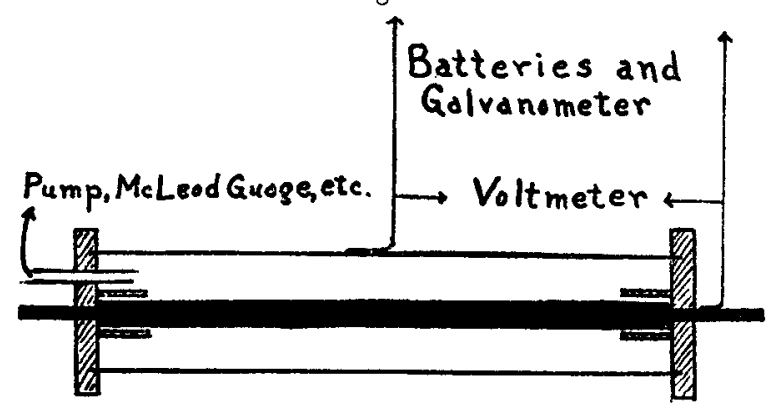

The apparatus used in the present experiments is represented in fig. 1. A brass cylinder, about $20 \mathrm{~cm}$. in length

* Communicated by Prof. J. S. Townsend, F.R.S.

+ 'The Theory of Ionization of Gases by Collision,' John S. Townsend, p. 54 . 